\title{
Quality of life in participants of a CRC screening program
}

\section{A Kapidzic*,', IJ Korfage², L van Dam', AHC van Roon', JCIY Reijerink ${ }^{3}$, AG Zauber ${ }^{4}$, M van Ballegooijen², EJ Kuipers ${ }^{1,5}$ and ME van Leerdam'}

'Department of Gastroenterology and Hepatology, Rotterdam, The Netherlands; '2Department of Gastroenterology and Hepatology, Public Health, Rotterdam, The Netherlands; ${ }^{3}$ Association of Nationwide Screening South-western Netherlands, Vlaardingen, The Netherlands; ${ }^{4}$ Department of Epidemiology and Biostatistics, Memorial Sloan-Kettering Cancer Center, New York, NY, USA; ${ }^{5}$ Department of Gastroenterology and Hepatology, Internal Medicine, Erasmus University Medical Centre, Rotterdam, The Netherlands

BACKGROUND: Little is known about the effect of participating in a colorectal cancer (CRC) screening programme on quality of life $(\mathrm{QOL})$, neither for participants with a negative nor for those with a positive test result. These findings, however, are important to evaluate the impact of CRC screening.

METHODS: Participants from CRC screening trials were sent a questionnaire, which included validated measures on generic health-related QOL, generic anxiety and screen-specific anxiety. Both faecal immunochemical test (FIT) and flexible sigmoidoscopy (FS) participants, either with negative or positive test results, were addressed.

RESULTS: The response rate was 73\% ( 1289 out of I 772) for FIT and 78\% (536 out of 689) for FS participants, with mean ages varying from 63-66 years. Positive FIT participants had worse physical (PCS-12, 47.I vs 48.3, P=0.02), but equal mental QOL scores (MCS-12, 5I.I vs 5 I.6, P=0.26). Positive and negative FS participants had similar QOL scores. Both FIT and FS participants with a positive test result reported more screen-specific anxiety than negative FIT and FS participants. Positive and negative FS participants had similar generic anxiety scores.

CONCLUSION: Our findings indicate that the burden of participating in CRC screening may be limited. Conducting a prospective study to confirm these results is recommended.

British Journal of Cancer (2012) I07, |295-1301. doi:I0.1038/bjc.2012.386 www.bjcancer.com

Published online 6 September 2012

(C) 2012 Cancer Research UK

Keywords: colorectal cancer screening; quality of life; faecal immunochemical test; flexible sigmoidoscopy; screen-specific anxiety

Worldwide, colorectal cancer (CRC) is the third most common malignancy in males and the second most common in females (Jemal et al, 2011). Colorectal cancer is the second cause of cancer-related death in developed countries (Center et al, 2009; Jemal et al, 2011). Five-year survival is over $90 \%$ when the disease is detected in an early stage (stage I), compared with $<10 \%$ for CRC with distant metastases (stage IV). Population-based screening programs can reduce CRC-related mortality by early detection and treatment of CRC, but also by removal of premalignant lesions (adenoma) (Mandel et al, 1993; Nicholson et al, 2005; Atkin et al, 2010).

Different CRC screening tests are available. These mainly include faecal occult blood tests (FOBTs) and endoscopy, in particular flexible sigmoidoscopy (FS) and colonoscopy. The latter techniques enable visualisation of a part or of the entire colon. However, these techniques are more invasive and more expensive than FOBTs. Randomised controlled trials (RCTs) showed that screening by means of FOBTs followed by colonoscopy if indicated, reduces CRC-related mortality by 15-33\% (Hewitson et al, 2008; Pizzo et al, 2011). More recently, a RCT with a median follow-up of 11.2 years from the UK showed that once-only FS screening between 55 and 64 years of age can substantially reduce colorectal cancer incidence and mortality (Atkin et al, 2010), although another similar FS screening RCT did not observe a mortality reduction after 7 years (Hoff et al, 2009).

*Correspondence: A Kapidzic; E-mail: a.kapidzic@erasmusmc.nl Received 23 May 2012; revised 6 August 2012; accepted 7 August 2012; published online 6 September 2012
Several Western countries have started or are considering introduction of FOBT or FS screening. In both FOBT- and FS-based screening programs, participants with a positive test are referred for colonoscopy. In the decision on the introduction of a population-based CRC screening programme, benefits such as life-years gained due to early detection and subsequent early treatment need to be outweighed against the burden of screening, such as the anxiety and distress due to participation, both with respect to the invitation and the test itself, as well as related to positive test results, whether truly or false positive. Anxiety in a screened population has previously been assessed for PAP smear results in cervical screening, where scores for generic and screenspecific anxiety were significantly higher in women with an abnormal smear (Korfage et al, 2010). The only two studies that investigated quality of life (QOL) effects in CRC screening showed that screening did not appear to have adverse emotional effects in the longer term ( $>4$ weeks) (Taylor et al, 2004; Taupin et al, 2006). These studies were focussed on colonoscopy- and FS-based screening. More information on QOL among participants in CRC screening is needed.

In this study, we aimed to assess QOL of participants in a FOBT- and FS-based CRC screening programme. The main research question of the study was whether QOL differed in participants with a positive test result compared with participants with a negative test result, and whether QOL differed between participants with true- and false-positive results. Furthermore, we evaluated whether differences in QOL were related to age, gender and social economic status. These findings can help to determine 
the impact of CRC screening, so quality of life and anxiety of a CRC screening programme can be clarified.

\section{MATERIALS AND METHODS}

\section{Study population}

Between November 2006 and December 2010, two Dutch population-based randomised CRC screening trials (CORERO-I and -II trial) were conducted in the southwest of the Netherlands with a target population of approximately 350000 inhabitants. Averagerisk individuals, aged between 50 and 74 years, were invited and if eligible included for FS or successive rounds of faecal immunochemical test (FIT) screening (Hol et al, 2010; van Roon et al, 2012). Within this cohort we conducted a retrospective observational study between December 2010 and April 2011. We addressed all participants of the CORERO-I or -II trial who had a positive screening test and a random sample of participants with a negative screening test (reference group).

An FIT value of $\geqslant 50 \mathrm{ng} \mathrm{ml}^{-1}$ was considered positive. A positive FS was defined as a sigmoidoscopy that revealed a polyp with a diameter $\geqslant 10 \mathrm{~mm}$; an adenoma with $\geqslant 25 \%$ villous component or high-grade dysplasia; serrated adenoma; $\geqslant 3$ adenomas; $\geqslant 20$ hyperplastic polyps; or CRC (Hol et al, 2010). Positive participants were referred for colonoscopy. All positive FIT participants were addressed and an equal number of controls was randomly selected (negative FIT participants). All positive FS participants were addressed as well. Because of power considerations we randomly selected twice as many controls, that is negative FS participants.

All selected screen participants were addressed with a questionnaire (see below for further details), an informed consent form and an accompanying letter, asking them to complete and return the questionnaire. A reminder was sent after 4 weeks to all nonrespondents. It was clarified in the letter that the choice to not participate in this questionnaire study would not have any consequences for health care or follow-up. The data on the amount of time that had elapsed between participation in the CRC screening programme and completion of the questionnaire were obtained through the regional screening organisation. Information on gender, age, marital status, income, education, country of birth and comorbidity was obtained through the questionnaire. Educational level was classified as low (primary school or lower technical education), intermediate or high (college/university degree).

\section{Content of the questionnaire}

The questionnaire included the following validated measures.

Generic HRQoL was assessed through the 12-item Short-Form Health Survey (SF-12) and the EuroQol classification (EQ-5D). The SF-12 consists of 12 items in the physical and mental domains. These 12 items are used to construct physical and mental summary measures (PCS-12 and MCS-12; scoring range from 0-100) (Gandek et al, 1998). Age- and sex-adjusted SF-12 norm scores are available from Statistics Netherlands (2010).

The EQ-5D classification consists of five items (mobility, selfcare, usual activities, pain/discomfort and anxiety/depression). Classification scores can be linked to a utility score with 0 indicating 'death' and 1 indicating 'full health' (Dolan, 1997). The EQ-5D is complemented by a visual analogue scale on current health, the valuation of own health, which is anchored at the lower end ( 0 ) by 'worst imaginable health state' and at the upper end (100) by 'best imaginable health state'.

Generic anxiety was assessed by the STAI-6, a validated short version of the State Trait Anxiety Inventory, containing six items on, for example, feeling at ease or upset. Scores range from 20 (almost never anxious) to 80 (almost always anxious), with higher scores correlating with greater anxiety. A STAI-score of over 44 defines an individual as highly anxious (Millar et al, 1995). To measure the screen-specific anxiety (that is the psychological impact of a positive CRC screening test) we used the Psychological Consequences Questionnaire (PCQ). The PCQ measures the consequences of screening on three dimensions, that is emotional, physical and social functioning. Ratings for symptoms within each dimension vary from 0 (not at all) to 3 (quite a lot of time). The added ratings indicate the level of dysfunction with higher scores indicating more dysfunction. As the subscales are highly correlated, we also report an overall PCQ score (score range $0-36)$. We used the Dutch version as adapted by Rijnsburger et al (2006).

Perceived risk of developing CRC was assessed through a Cancer Worry Scale (CWS) (Gramling et al, 2007). The CWS consists of items such as 'During the last week, how often have you thought about your own chances of developing cancer?' and; 'During the last week, how often have thoughts about getting cancer affected your mood?'. For each question, participants were given the following four response items: 'Not at all or Rarely', 'Sometimes', 'Often' and 'Almost all the time'.

Furthermore, the questionnaire included items on how people make decisions regarding their health in general and how people look back at the screening procedure as a whole. This last topic contained questions on whether people would participate in the CRC screening programme again and whether participants would recommend participating to a friend or relative.

\section{Statistical analyses}

In accordance with the guidelines missing items in the STAI and PCQ scales were imputed by participants' own average score if at least $50 \%$ of these items had been completed (Ware et al, 1993). To assess non-response bias we compared gender and age of the respondents with those of the non-respondents. Differences between the groups in background variables, in health-related QOL, generic and screen-specific anxiety scores, worries regarding cancer and in general attitude towards screening were assessed using Mann-Whitney $U$ tests for continuous variables and $\chi^{2}$ tests for categorical ones.

We tested the relationship between generic anxiety and screenspecific anxiety scores on the one hand and the time period that had elapsed since the screening on the other hand, by comparing scores of participants who had a screening test 4-12 months before completion of the questionnaire $v s$ 12-24 months $v s>24$ months. Furthermore, we examined whether QOL scores differed between FIT participants with a true and false-positive test result.

Statistical analyses were performed using SPSS for Windows, version 15. A $P$-value $<0.05$ (referring to two-sided statistical tests) was considered significant. The ethics review committee of the Erasmus MC, University Medical Center Rotterdam, approved the research protocol (MEC-2010-411).

\section{RESULTS}

\section{Response and respondent characteristics}

All participants of the CORERO-I and -II trial who had either a positive FIT result (cutoff $50 \mathrm{ng} \mathrm{ml}^{-1}, n=857$ ) or a positive FS $(n=227)$ were sent a questionnaire $(n=1084)$. A questionnaire was also sent to a randomly selected group of 1377 participants with a negative screening test (i.e., a negative FIT (915 out a total of 7825 participants) or a negative FS (462 out of a total of 1971 participants)). All FS participants participated in the CRC screening programme 3-5 years before filling out the questionnaire, with a mean interval time of 44 months. The FIT participants participated in the CRC screening programme varying from 5 

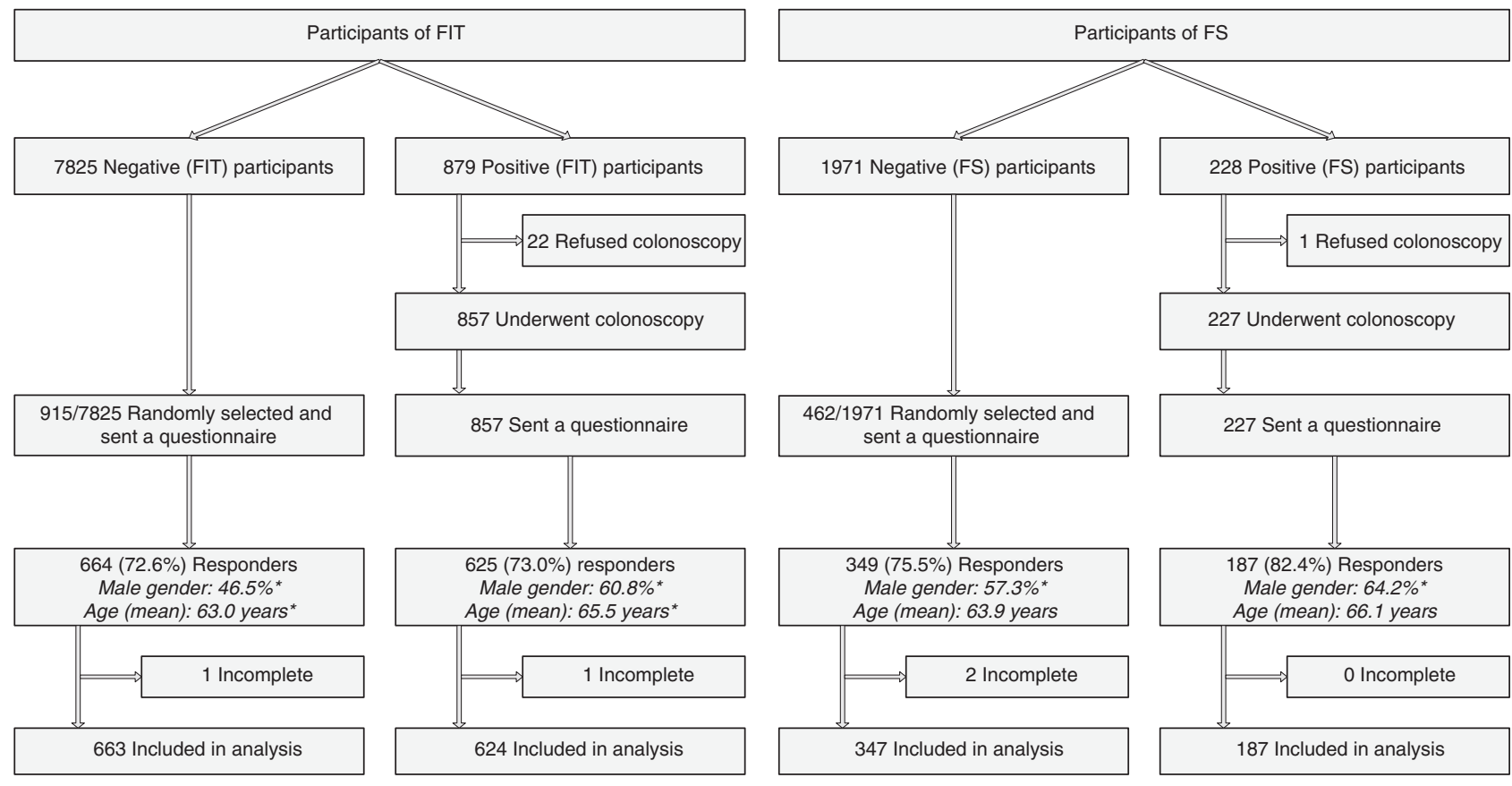

*: statistical significant difference $(P<0.05)$ between responders and non-responders within the same screening strategy

Figure I Flowchart of study responders.

years to 4 months before filling out the questionnaire, with a mean interval time of 15 months and 26 months, respectively, for negative and positive FIT participants (data not shown).

Response rates for FIT and FS participants varied between 73 and $82 \%$ (Figure 1). The respondents' characteristics are shown in Table 1. Participants with a positive FIT result were more often male $(60.8 \%$ vs $46.5 \%, P<0.001)$ and were older than participants with a negative FIT result (mean age 65.5 vs 63.0 years, $P<0.001$ ). A similar pattern was seen in FS participants: more were males (64.2\% vs $57.3 \%$ males, $P=0.125)$ and were older of age (mean age 66.1 vs 63.9 years, $P<0.001$ ) in the group with a positive test result. No differences were observed with respect to education, income, marital status and country of birth between those with a positive and negative test result. Compared with non-responders, responders in the FIT group were more often male (53\% vs $42 \%$, $P<0.001)$. No differences in age existed between these two groups. There were no differences regarding gender distribution and age between FS responders and non-responders (data not shown).

\section{Quality of life scores}

Generic QOL SF-12 scores regarding physical health were significantly lower in FIT participants with a positive test result than in those with a negative result, indicating worse functioning in this group (Table 2). Furthermore, positive FIT participants had significantly worse EQ-5D scores and rated their own health worse than participants with a negative test result. The QOL scores did not differ between positive and negative FS participants. When comparing the SF-12 scores to the age-adjusted norm scores for the Dutch population, we found that for both FIT and FS participants of $\geqslant 65$ years, the PCS-12 scores were higher, indicating better physical functioning in participants than in the general population (CBS StatLine). The FIT participants under the age of 65 showed worse physical functioning compared with the general population. No difference was seen for FS participants under the age of 65 . The mental health-related QOL scores were lower than those in the general population, indicating worse mental functioning in our participants (CBS StatLine).
Genereric anxiety and screen-specific anxiety The STAI-6 score was significantly lower in FIT participants with a positive test result, indicating less generic anxiety in these participants compared with negative FIT participants (Table 2). The STAI-6 scores did not differ between positive and negative FS participants. Total PCQ scores were significantly higher in FIT and FS participants with a positive test result, indicating more screenspecific anxiety in these participants compared with participants with a negative test result (Table 2).

No statistically significant differences were found in generic anxiety, screen-specific anxiety and QOL scores between negative FIT participants and positive FIT participants who underwent a colonoscopy 4-12 months vs 12-24 months $v s>24$ months before completion of the questionnaire (Tables $3 \mathrm{~A}$ and $\mathrm{B}$ ). The QOL scores, generic anxiety and screen-specific anxiety did not differ between positive FIT participants who subsequently had a negative (false-positive FIT) vs a positive (true-positive FIT) colonoscopy (Table 4).

\section{Overall acceptance}

The vast majority of FIT participants would encourage friends and/or relatives to undergo screening (negative FIT participants: 95\%, positive FIT participants: $92 \% ; P=0.060)$ and was willing to attend a successive screening round (negative FIT participants: $99 \%$, positive FIT participants $92 \% ; P<0.001$ ) (Figure 2). The same positive attitude towards screening was found in FS participants, who reported similarly high scores for encouraging friends and/or relatives to undergo screening (negative FS participants: $97.4 \%$, positive FS participants: $99.4 \% ; P=0.024)$ and willingness to attend a successive screening round (negative FS participants: 92.7\%, positive FS participants: $95.6 \%$; $P=0.253$ ).

\section{DISCUSSION}

This study examined the QOL of participants in a CRC screening programme. The response rate was high. Participants with 
Table I Background characteristics of responders by type of CRC screening

\begin{tabular}{|c|c|c|c|c|c|c|}
\hline & \multicolumn{3}{|c|}{ Faecal immunochemical test } & \multicolumn{3}{|c|}{ Flexible sigmoidoscopy } \\
\hline & $\begin{array}{c}\text { Negative test } \\
\text { result }(n=663)\end{array}$ & $\begin{array}{l}\text { Positive test } \\
\text { result }(n=624)\end{array}$ & $P$-value & $\begin{array}{l}\text { Negative test } \\
\text { result }(n=347)\end{array}$ & $\begin{array}{l}\text { Positive test } \\
\text { result }(n=187)\end{array}$ & $P$-value \\
\hline \multicolumn{7}{|l|}{ Age (years) } \\
\hline Mean (s.d.) & $63.0( \pm 6.1)$ & $65.5( \pm 6.4)$ & $<0.001$ & $63.9( \pm 6.3)$ & $66.1( \pm 6.7)$ & $<0.001$ \\
\hline Male gender (\%) & $308(46.5)$ & $380(60.8)$ & $<0.001$ & $199(57.3)$ & $120(64.2)$ & 0.13 \\
\hline Low & 211 (32.3) & $209(34.4)$ & & $106(31.1)$ & 61 (33.2) & \\
\hline Medium & $273(41.8)$ & $267(43.9)$ & & $142(41.7)$ & 69 (37.5) & \\
\hline High & $169(25.8)$ & $129(21.2)$ & & $92(26.9)$ & $52(28.2)$ & \\
\hline Income (\%) & & & 0.08 & & & 0.82 \\
\hline$<22.125$ euros & | $78(3||)$. & $174(32.6)$ & & $86(28.7)$ & $52(31.4)$ & \\
\hline $22.125-44.250$ euros & $248(43.3)$ & $237(44.4)$ & & $130(43.3)$ & 71 (42.8) & \\
\hline Country of birth (\%) & & & 0.85 & & & 0.41 \\
\hline The Netherlands & $616(93.5)$ & $579(94.3)$ & & $316(92.4)$ & $177(95.2)$ & \\
\hline
\end{tabular}

Abbreviation: $C R C=$ colorectal cancer

Table 2 Mean scale scores of responders with a negative and responders with a positive test result

\begin{tabular}{|c|c|c|c|c|c|c|}
\hline & \multicolumn{3}{|c|}{ Faecal immunochemical test } & \multicolumn{3}{|c|}{ Flexible sigmoidoscopy } \\
\hline & $\begin{array}{l}\text { Negative test } \\
\text { result }(n=663)\end{array}$ & $\begin{array}{l}\text { Positive test } \\
\text { result }(n=624)\end{array}$ & $P$-value & $\begin{array}{l}\text { Negative test } \\
\text { result }(n=347)\end{array}$ & $\begin{array}{l}\text { Positive test } \\
\text { result }(n=187)\end{array}$ & $P$-value \\
\hline \multicolumn{7}{|l|}{ Generic HRQoL } \\
\hline \multicolumn{7}{|l|}{ SF-12 $(0-100)^{\mathrm{a}}$} \\
\hline Physical health (PCS-12) & $48.3(8.9)$ & $47.1(9.4)$ & 0.02 & $48.1(8.8)$ & $47.0(9.3)$ & 0.20 \\
\hline Mental health (MCS-12) & $51.6(8.9)$ & $51.1(9.2)$ & 0.26 & $52.0(8.5)$ & $50.3(9.6)$ & 0.11 \\
\hline EQ-5D (0-1) & $0.85(0.19)$ & $0.82(0.20)$ & 0.02 & $0.85(0.17)$ & $0.80(0.24)$ & 0.13 \\
\hline Rating of own health $(0-100)$ & $77.3(16.7)$ & $74.5(16.9)$ & $<0.001$ & $76.5(16.6)$ & $72.8(18.6)$ & 0.01 \\
\hline \multicolumn{7}{|l|}{ Generic anxiety ${ }^{\mathrm{a}}$} \\
\hline STAI-6 (20-80) & $43.8(5.2)$ & $43.3(5.2)$ & 0.03 & $42.6(4.8)$ & $43.3(4.5)$ & 0.25 \\
\hline \multicolumn{7}{|l|}{ Screen-specific anxiety ${ }^{\mathrm{a}}$} \\
\hline
\end{tabular}

Abbreviations: $\mathrm{EQ}-5 \mathrm{D}=$ European quality of Life-5 dimensions; EuroQoL = European quality of life; HRQoL=health-related quality of life; MCS- $12=$ Mental Component Health-related Quality of Life Score; PCQ = Psychological Consequences Questionnaire; PCS- 12 = Physical Component Health-related Quality of Life Scores; SF- 12 = Medical Outcomes Study 12-Item Short-form Health Survey; STAl-6 = Six-item State Trait Anxiety Inventory. ${ }^{\mathrm{a} F o r}$ SF-12 and EuroQoL a higher score indicates better health. For Generic anxiety and screen-specific anxiety a higher score indicates more anxiety.

a positive FIT had slightly worse QOL scores than participants with a negative FIT test. Furthermore, no significant differences were seen in QOL scores between positive FIT participants with either a negative or a positive colonoscopy. No differences were found in QOL scores between positive and negative FS participants. Both FIT and FS participants with a positive test result had higher PCQ scores than negative participants, indicating more screen-specific anxiety in these groups. Overall, these findings may indicate that the burden of participating in a CRC screening programme is limited.

Few studies investigated QOL in relation to CRC screening. Taupin et al (2006) performed a study among primary colonoscopy screening participants. Participants completed the Short-Form (SF-36) QOL assessment at baseline and at a mean of 39 days after colonoscopy. Baseline QOL measures were similar to those of a matched general population sample. Thirty percent of all participants reported positive changes in mental health and vitality after colonoscopy, irrespective of the outcome. Unfortunately, long-term effects on QOL were not assessed. The PLCO Trial (Prostate, Lung, Colorectal and Ovarian Cancer Screening Trial) investigated QOL among screening FS participants (Taylor et al, 2004). The FS participants were interviewed by telephone at different time intervals (at baseline, shortly after notification and nine months after notification of screening results). Control-arm 
Table 3A Mean scale scores of responders with a negative test result, for the whole group and per time period passed between participation in the screening programme and filling out the questionnaire

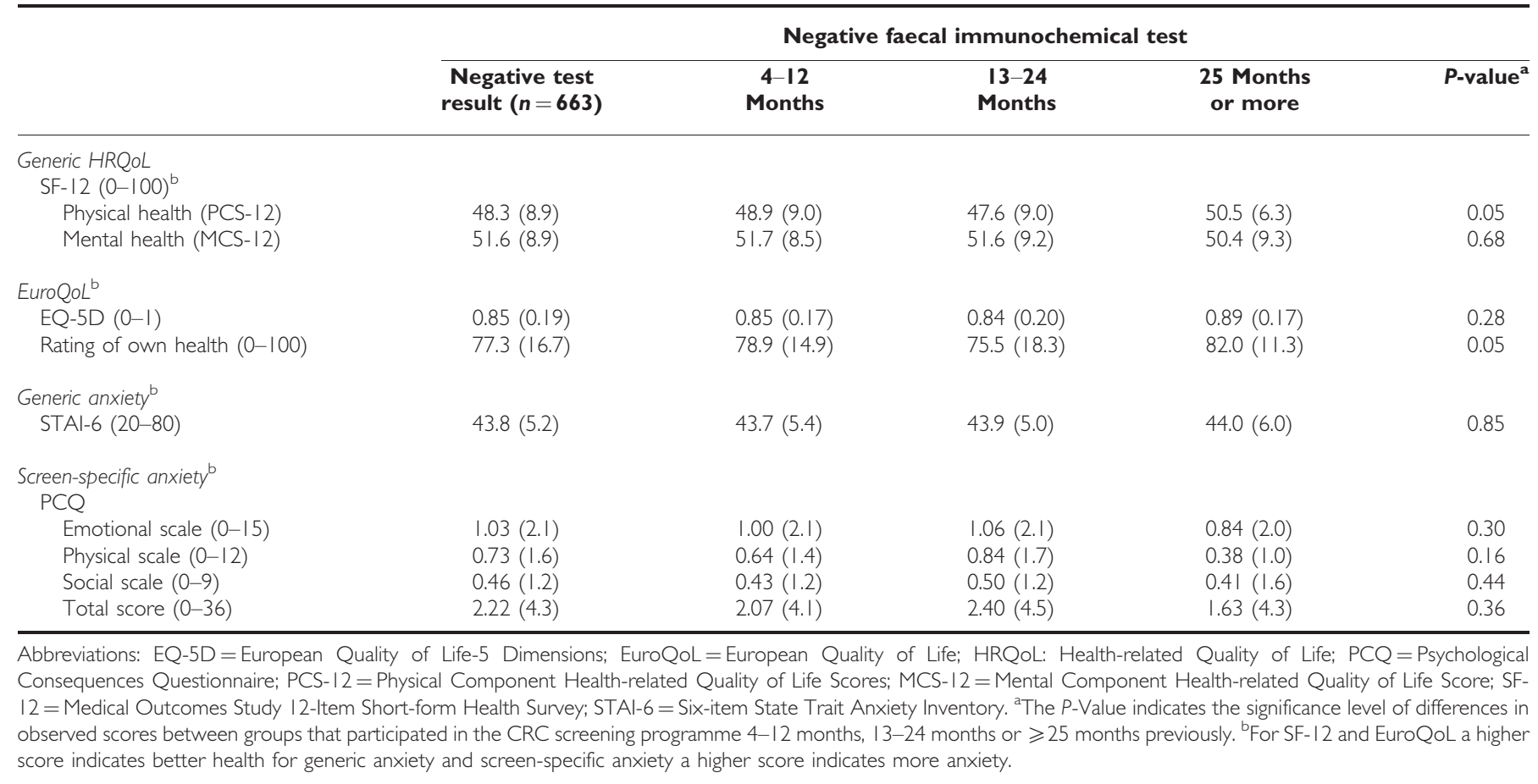

Table 3B Mean scale scores of responders with a positive test result, for the whole group and per time period passed between participation in the screening programme and filling out the questionnaire

\begin{tabular}{|c|c|c|c|c|c|}
\hline & \multicolumn{5}{|c|}{ Positive faecal immunochemical test } \\
\hline & Positive test result $(n=624)$ & 4-12 Months & 13-24 Months & 25 Months or more & $P$-value ${ }^{a}$ \\
\hline Physical health (PCS-12) & $47.1(9.4)$ & $47.4(10.1)$ & $46.7(10.4)$ & $47.1(8.7)$ & 0.61 \\
\hline Mental health (MCS-12) & $51.1(9.2)$ & $52.5(8.5)$ & $50.8(10.0)$ & $50.8(9.1)$ & 0.26 \\
\hline \multicolumn{6}{|l|}{ EuroQoL ${ }^{b}$} \\
\hline Rating of own health $(0-100)$ & $74.5(16.9)$ & $77.4(13.1)$ & $72.9(18.9)$ & $74.5(16.6)$ & 0.32 \\
\hline \multicolumn{6}{|l|}{ Generic anxiety ${ }^{b}$} \\
\hline STAI-6 (20-80) & $43.3(5.2)$ & $42.8(5.4)$ & $43.4(4.8)$ & $43.5(5.3)$ & 0.53 \\
\hline \multicolumn{6}{|l|}{ Screen-specific anxiety ${ }^{\mathrm{b}}$} \\
\hline \multicolumn{6}{|l|}{ PCQ } \\
\hline
\end{tabular}

Abbreviations: EQ-5D = European Quality of Life-5 Dimensions; EuroQoL=European Quality of Life; HRQoL: Health-related Quality of Life; PCQ = Psychological Consequences Questionnaire; PCS-12 = Physical Component Health-related Quality of Life Scores; MCS-12=Mental Component Health-related Quality of Life Score;

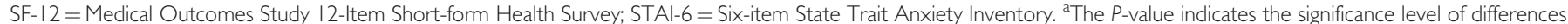
in observed scores between groups that participated in the CRC screening programme 4-12 months, 13-24 months or $\geqslant 25$ months previously. ${ }^{b}$ For SF-12 and EuroQoL a higher score indicates better health. For generic anxiety and screen-specific anxiety a higher score indicates more anxiety.

participants (no screening) completed a baseline and 1-year follow-up assessment. After 9 months FS participants with abnormal screening results did not show higher levels of intrusive thoughts about cancer than those with normal results $(P=0.096$; odds ratio $(\mathrm{OR})=1.9,95 \%$ confidence interval $(\mathrm{CI})=0.89-4.2)$. These results are in line with our study, where we found similar QOL scores among negative and positive FS participants.
In our study, we found that both FIT and FS participants with a positive test result showed significantly more screen-specific anxiety than participants with a negative test result. To indicate clinical relevance we used the minimal important difference (MID), defined as the smallest change in a patient-reported outcome that is perceived by patients as beneficial or that would result in a change of treatment. The MID was operationalised as a 
difference of at least half a s.d. (Norman et al, 2003). Although some differences in QOL scores were statistifically significant, all differences in QOL scores between negative and positive FIT and FS participants were rather small and none of them exceeded the MID. These are therefore not clinically relevant. Two other studies among participants in a FOBT-screening programme and one FS screening study, assessing worries associated with CRC screening, showed that most of the participants did not experience an increase in anxiety (Lindholm et al, 1997; Thiis-Evensen et al, 1999; Parker et al, 2002). Control groups consisted of an age- and gender-matched group not invited for screening (Thiis-Evensen et al, 1999; Parker et al, 2002) and persons who had received the invitation letter but had not attended the screening programme (Lindholm et al, 1997). Furthermore, participants did not develop adverse psychological effects 17 months after screening (Lindholm et al, 1997; Parker et al, 2002).

Table 4 Mean scale scores of responders with a positive test result (FIT) by result of the colonoscopy

\begin{tabular}{|c|c|c|c|}
\hline & $\begin{array}{c}\text { Negative } \\
\text { colonoscopy } \\
\text { after positive } \\
\text { FIT } \\
(n=288)\end{array}$ & $\begin{array}{c}\text { Positive } \\
\text { colonoscopy } \\
\text { after } \\
\text { positive FIT } \\
(n=184)\end{array}$ & $P$-value \\
\hline \multicolumn{4}{|l|}{ Generic HRQoL } \\
\hline Physical health (PCS-12) & $46.7(9.7)$ & $47.6(9.1)$ & 0.34 \\
\hline Mental health (MCS-12) & $50.8(9.1)$ & $51.4(9.5)$ & 0.29 \\
\hline \multicolumn{4}{|l|}{ EuroQol ${ }^{a}$} \\
\hline EQ-5D (0-1) & $0.81(0.21)$ & $0.82(0.22)$ & 0.14 \\
\hline Rating of own health $(0-100)$ & $74.2(16.7)$ & $75.7(15.9)$ & 0.29 \\
\hline \multicolumn{4}{|l|}{ Generic anxiety ${ }^{\mathrm{a}}$} \\
\hline STAI-6 (20-80) & $43.5(4.9)$ & $43.5(5.4)$ & 1.00 \\
\hline \multicolumn{4}{|l|}{ Screen-specific anxiety ${ }^{\mathrm{a}}$} \\
\hline \multicolumn{4}{|l|}{ PCQ } \\
\hline Emotional scale $(0-15)$ & $1.74(2.7)$ & $1.76(2.7)$ & 0.82 \\
\hline Physical scale $(0-12)$ & $1.06(1.8)$ & $1.09(2.0)$ & 0.72 \\
\hline Social scale (0-9) & $3.60(5.3)$ & $0.80(1.7)$ & 0.18 \\
\hline Total score (0-36) & $0.81(1.4)$ & $3.65(5.7)$ & 0.97 \\
\hline
\end{tabular}

Abbreviations: $\mathrm{EQ}-5 \mathrm{D}=$ European Quality of Life-5 Dimensions; EuroQoL $=$ European Quality of Life; FIT = faecal immunochemical test; HRQoL $=$ Healthrelated Quality of Life; MCS-12 = Mental Component Health-related Quality of Life Score; $\quad \mathrm{PCQ}=$ Psychological $\quad$ Consequences Questionnaire; $\quad$ PCS-12 = Physical Component Health-related Quality of Life Scores; SF-12 = Medical Outcomes Study 12-Item Short-form Health Survey; STAI-6 = Six-item State Trait Anxiety Inventory. ${ }^{a}$ For SF- 12 and EuroQoL a higher score indicates better health. For generic anxiety and screen-specific anxiety a higher score indicates more anxiety.
Literature on CRC screening shows that even in subjects with a false-positive test result, screening for CRC has no adverse effect on anxiety on the long-term (Parker et al, 2002; Brasso et al, 2010). Population-based screening studies regarding prostate and breast cancer found similar results (Sutton et al, 1995; Essink-Bot et al, 1998). Apparently, a false-positive test result does not negatively affect participants' QOL. These findings are in accordance with our study, as QOL scores were similar in positive FIT participants with either a negative or a positive colonoscopy. Possible explanations for these mainly positive effects of CRC screening in participants with a true-positive result could be that, although participants are worried because of the possibility of having colorectal cancer, they are either simultaneously relieved that they found out on time and will be screened regularly to prevent colorectal cancer, or they are reassured because they soon underwent treatment. In case of a false-positive result, we hypothesised that participants are relieved that no abnormalities were found during further investigations.

In our study, we addressed large numbers of participants in a CRC screening programme. Both participants with a positive and negative test result who underwent either FOBT or FS were included. Another strength is that the response rate to the questionnaire was high. Furthermore, validated measures were used to assess QOL and we were able to compose a questionnaire that enables to understand the impact of screening on participants' QOL. A review of instruments to measure the QOL of participants in a CRC screening programme reinforced the importance of such a questionnaire (Pizzo et al, 2011). We unfortunately have no information on QOL of non-participants, and we have no information on QOL, nor psychological or physical, before FIT or FS testing. These baseline values are essential to make a correct comparison, and to correct the effect of factors such as age (screen-positive participants were older than screen-negative participants). Participants in a screening study might not reflect the general population and might react differently. We did, however, look at mean SF-12 scores in the general Dutch population. Furthermore, we don't have data on QOL and anxiety of the entire screening process (e.g., after performing the screening test, while waiting for the test result, after colonoscopy, and so on). Because the majority of responders were of Caucasian ethnicity, our results cannot be extrapolated to a non-Caucasian population. Further studies in a non-Caucasian population are therefore needed.

In summary, this retrospective questionnaire survey on QOL among participants of a FIT or FS CRC screening programme showed slightly worse QOL scores among positive FIT participants compared with FIT negative participants. Compared with the general Dutch population, mental health-related QOL scores were lower among all participants. Screen-specific anxiety was significantly higher among both positive FIT and FS participants, indicating that a positive test result has a negative impact on participants' emotional well-being, although differences were small
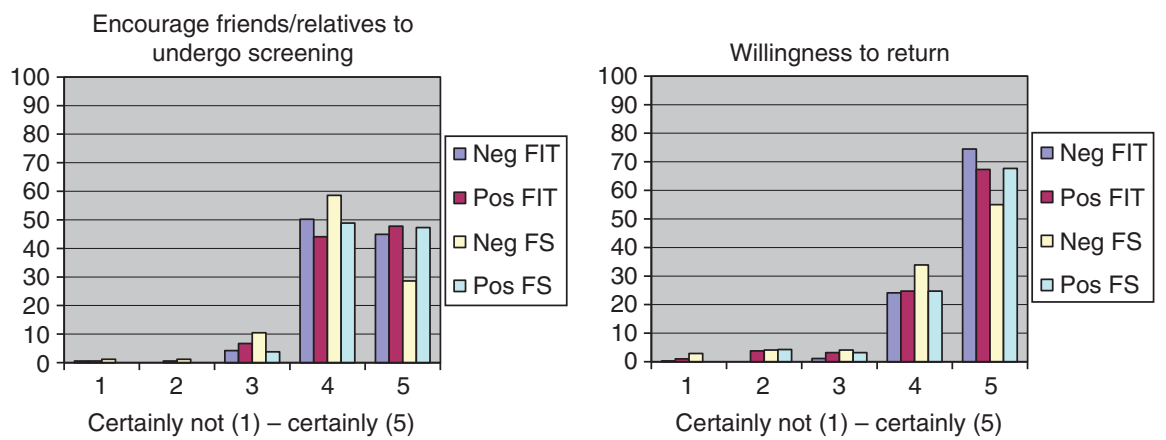

Figure 2 Scores on the advice subjects would give and willingness to return. Using a 5-point Likert scale (0-100 scale): scores on the advice subjects would give others to participate in screening and willingness of screenees to return for successive screening rounds. 
and not clinically relevant. With respect to cost-effectiveness analyses that aim to assess quality-adjusted life-years lost or gained by screening, our results suggest that the impact of FIT and FS screening on experienced QOL after the screening process will be modest. A prospective study needs to be conducted, where participants receive questionnaires at different time points during the entire screening process. Only this way, we will fully be able to

\section{REFERENCES}

Atkin WS, Edwards R, Kralj-Hans I, Wooldrage K, Hart AR, Northover JM, Parkin DM, Wardle J, Duffy SW, Cuzick J, Investigators, U.K.F.S.T. (2010) Once-only flexible sigmoidoscopy screening in prevention of colorectal cancer: a multicentre randomised controlled trial. Lancet 375 : 1624-1633

Brasso K, Ladelund S, Frederiksen BL, Jorgensen T (2010) Psychological distress following fecal occult blood test in colorectal cancer screening-a population-based study. Scand J Gastroenterol 45: 1211-1216

Center MM, Jemal A, Smith RA, Ward E (2009) Worldwide variations in colorectal cancer. CA Cancer J Clin 59: 366-378

Dolan P (1997) Modeling valuations for EuroQol health states. Med Care 35: $1095-1108$

Essink-Bot ML, de Koning HJ, Nijs HG, Kirkels WJ, van der Maas PJ, Schroder FH (1998) Short-term effects of population-based screening for prostate cancer on health-related quality of life. J Natl Cancer Inst 90: 925-931

Gandek B, Ware JE, Aaronson NK, Apolone G, Bjorner JB, Brazier JE, Bullinger M, Kaasa S, Leplege A, Prieto L, Sullivan M (1998) Crossvalidation of item selection and scoring for the SF-12 Health Survey in nine countries: results from the IQOLA Project. International Quality of Life Assessment. J Clin Epidemiol 51: 1171-1178

Gramling R, Anthony D, Frierson G, Bowen D (2007) The cancer worry chart: a single-item screening measure of worry about developing breast cancer. Psychooncology 16: 593-597

Hewitson P, Glasziou P, Watson E, Towler B, Irwig L (2008) Cochrane systematic review of colorectal cancer screening using the fecal occult blood test (hemoccult): an update. Am J Gastroenterol 103: 1541-1549

Hoff G, Grotmol T, Skovlund E, Bretthauer M, Norwegian Colorectal Cancer Prevention Study, G (2009) Risk of colorectal cancer seven years after flexible sigmoidoscopy screening: randomised controlled trial. BMJ 338: b1846

Hol L, van Leerdam ME, van Ballegooijen M, van Vuuren AJ, van Dekken H, Reijerink JC, van der Togt AC, Habbema JD, Kuipers EJ (2010) Screening for colorectal cancer: randomised trial comparing guaiacbased and immunochemical faecal occult blood testing and flexible sigmoidoscopy. Gut 59: 62-68

Jemal A, Bray F, Center MM, Ferlay J, Ward E, Forman D (2011) Global cancer statistics. CA Cancer J Clin 61: 69-90

Korfage IJ, van Ballegooijen M, Huveneers H, Essink-Bot ML (2010) Anxiety and borderline PAP smear results. Eur J Cancer 46: 134-141

Lindholm E, Berglund B, Kewenter J, Haglind E (1997) Worry associated with screening for colorectal carcinomas. Scand J Gastroenterol 32: 238-245

Mandel JS, Bond JH, Church TR, Snover DC, Bradley GM, Schuman LM, Ederer F (1993) Reducing mortality from colorectal cancer by screening evaluate the impact of screening on QOL and anxiety and anticipate on possible negative side-effects.

\section{ACKNOWLEDGEMENTS}

We would like to thank CWN Looman for statistical advice. for fecal occult blood. Minnesota Colon Cancer Control Study. N Engl J Med 328: 1365-1371

Millar K, Jelicic M, Bonke B, Asbury AJ (1995) Assessment of preoperative anxiety: comparison of measures in patients awaiting surgery for breast cancer. Br J Anaesth 74: 180-183

Nicholson FB, Barro JL, Atkin W, Lilford R, Patnick J, Williams CB, Pignone M, Steele R, Kamm MA (2005) Review article: population screening for colorectal cancer. Aliment Pharmacol Ther 22: 1069-1077

Norman GR, Sloan JA, Wyrwich KW (2003) Interpretation of changes in health-related quality of life: the remarkable universality of half a standard deviation. Med Care 41: 582-592

Parker MA, Robinson MH, Scholefield JH, Hardcastle JD (2002) Psychiatric morbidity and screening for colorectal cancer. J Med Screen 9: 7-10

Pizzo E, Pezzoli A, Stockbrugger R, Bracci E, Vagnoni E, Gullini S (2011) Screenee perception and health-related quality of life in colorectal cancer screening: a review. Value Health 14: 152-159

Rijnsburger AJ, Essink-Bot ML, van As E, Cockburn J, de Koning HJ (2006) Measuring psychological consequences of screening: adaptation of the psychological consequences questionnaire into Dutch. Qual Life Res 15: 933-940

Statistics Netherlands (2010) Health, Lifestyle, Use of Medical Facilities. Centraal Bureau voor de Statistiek: Den Haag/Heerlen, The Netherlands

Sutton S, Saidi G, Bickler G, Hunter J (1995) Does routine screening for breast cancer raise anxiety? Results from a three wave prospective study in England. J Epidemiol Community Health 49: 413-418

Taupin D, Chambers SL, Corbett M, Shadbolt B (2006) Colonoscopic screening for colorectal cancer improves quality of life measures: a population-based screening study. Health Qual Life Outcomes 4: 82

Taylor KL, Shelby R, Gelmann E, McGuire C (2004) Quality of life and trial adherence among participants in the prostate, lung, colorectal, and ovarian cancer screening trial. J Natl Cancer Inst 96: 1083-1094

Thiis-Evensen E, Wilhelmsen I, Hoff GS, Blomhoff S, Sauar J (1999) The psychologic effect of attending a screening program for colorectal polyps. Scand J Gastroenterol 34: 103-109

van Roon AH, Goede SL, van Ballegooijen M, van Vuuren AJ, Looman CW, Biermann K, Reijerink JC, Mannetje HT, van der Togt AC, Habbema JD, van Leerdam ME, Kuipers EJ (2012) Random comparison of repeated faecal immunochemical testing at different intervals for population-based colorectal cancer screening. Gut; doi:10.1136/ gutjnl-2011-301583

Ware JEJ, Snow KK, Kosinski M, Gandek BG (1993) SF-36 Health Survey: Manual and Interpretation Guide. The Health Institute, New England Medical Center: Boston, MA

This work is published under the standard license to publish agreement. After 12 months the work will become freely available and the license terms will switch to a Creative Commons Attribution-NonCommercial-Share Alike 3.0 Unported License. 